\title{
Comparison between conventional and modern methods for extraction of Rosmarinus officinalis leaves
}

\section{Lana Yousif Mutalib *}

\section{Abstract}

Background and objective: The first step in the process of drug obtaining from natural origin was standardized extraction procedure. The aim of the study was to compare extracts of Rosemarinusofficinalis obtained by different methods of extraction from mass and phytochemical points.

Methods: Comparison was done through measuring the mass of yield of Rosmarinusofficinalis extracts using different methods of extraction. Qualitative analysiswas done through preliminary phytochemical screening tests for the presence of secondary natural groups of extracts of rosemary plant obtained by different methods of extraction.

Results: The highest yield mass $(7.666 \%)$ was obtained from the microwave assisted extraction method belong to the modern methods of extraction group. In qualitative analysis, there was no difference in the presence of the secondary natural product groups with different methods of extraction belonging to the two classes conventional and modern. New group of natural products were detected in the ethanolic plant extract are condensed tannin and quinone.

Conclusion: Microwave assisted extraction is considered as the most efficient method of extraction from quantitative measures. Qualitative analysis of ethanolic extract of Rosmarinusofficinalis shows presence of phytochemical compounds like condensed tannin, quinon, flavonoid, terpenoid and phenols.

Keywords: Rosemarinusofficinalis, Phytochemical screening, Microwave assisted extraction, Secondary natural group.

\section{Introduction}

The process of separation of active constituent from the inactive ones either from plant or animal tissues refers to the pharmaceutical term extraction, using selective solvent and standard procedures. The yield of extraction process is in form of liquid, solid (powder) or semisolid (pilular) known as decoctions, infusions, or tinctures according to the used standard extraction methods for extracting of the phytochemicals from the plant material. Preparation of the extraction process known as galenicals, named after Galen, the second century Greek physician. ${ }^{1}$ Extraction is the first crucial step in the screening process of the plant extracts for the desired phytochemicals in the medicinal plant product researches. ${ }^{2}$
Standardized extraction methods required for having complete view of bioactive compounds in the crude extracts and maximum extraction efficacy. ${ }^{3}$ Plant extracts with higher quality and efficiency can be obtained through an optimized extraction process. ${ }^{4}$ Plant extracts are used for many purposes either culinary, pharmaceutically or industrially due to the presence of valuable bioactive phytochemicals, lipids, flavors and pigments. There are many investigations for extracting these bioactive compounds from plants. However, conventional methods like maceration, infusion, and ordinary reflux are used for many decades in laboratories for extraction; main disadvantages are time and solvent consuming. Recently because of the backwards of the

* Department of Pharmacogonsy, College of Pharmacy, Hawler Medical University, Erbil, Iraq. 
conventional methods there is an increase needs for developing of the modern methods for extraction with the decreasing in the amount of solvent consumption and time consuming, example of these methods are ultrasound-assisted extraction, microwave-assisted extraction, which are working with higher efficiency, lesser solvent and high yield mass for extracting phytochemicals form solid plant material. ${ }^{5-10}$ Rosemary plant with the scientific name of Rosmarinus officinal is $L$. is of mint family Lamiaceae (Labiatae) family. Rose marry is a woody, perennial herb with an evergreen bush which is a local plant of Mediterranean region with pharmacological and decorative value. Generally Rosmarinusofficinalis herb is used for culinary purposes and spice, antioxidant and antimicrobial agent. ${ }^{11-14}$ Traditionally, rosemary has been used by herbalists to improve memory, relax muscles, relieve muscle pain and spasm, and stimulate hair growth, wedding ornaments, support the circulatory and nervous systems, in the prevention of cancer and its antibacterial properties. ${ }^{15}$ Main active constituents of Rosmarrinusofficinalis are flavonoids, phenolic acids, diterpenes, steroids, triterpene and essential oils. ${ }^{16,17}$

\section{Methods}

A- Plant Material:

Rosmarrinusofficinalis was collected from Safeen Mountain, Shaqlawa, ErbilKurdistan Region. The plant was authenticated by the Department of Pharmacognosy, College of Pharmacy, Hawler Medical University. The leaves were dried in shade and were used in the present study.

\section{B- Comparison Of Extraction Methods:}

The comparison was done through weighing the yield of the extraction process using different extraction methods, extraction methods used for comparison are arranged below from conventional ones to the more advanced procedures:

\section{1- Conventional Methods:}

Fifty gram of dried coarsely grounded rosemary leaves where introduce to different methods of extraction belonging to the conventional methods which are maceration, decoction, infusion, ordinary reflux, soxhelt extraction method using $150 \mathrm{ml}$ of $70 \%$ ethanol as a solvent of extraction with periods according to the method of extraction show in Table 1 using standardized procedures. ${ }^{1,18}$ The extracts where filtered separately and concentrated using rotary-vapor machine and stored at $40{ }^{\circ} \mathrm{C}$ until dried.

Table 1: Periods in procedures used in conventional extractions methods.

\begin{tabular}{ll}
\hline Method of Extraction & Period \\
\hline Maceration & 3 days \\
Maceration & 7 days \\
Infusion & 10 minutes \\
Decoction & 15 minutes \\
Ordinary Reflux & 1 hour \\
Soxhelt Extraction method & 2 hours \\
\hline
\end{tabular}

\section{2- MODERN METHODS:}

\section{Ultrasonic Assisted Extractor (UAE):}

Fifty gram of dried coarsely grounded rosemary leaves mixed with $150 \mathrm{ml}$ of $70 \%$ ethanol extracted using ultrasonic assisted extractor for 1 hrat $40{ }^{\circ} \mathrm{C}$ were filtered and reduced in volume by rotary-vapor machine and stored in oven at $40^{\circ} \mathrm{Cuntil}$ dried. ${ }^{19}$

\section{Microwave Assisted Extractor (MAE):}

Extraction was carried out according to the Quan, Hang method ${ }^{20}$ with slight modification. In domestic microwave oven (MWF 2310, BEKO), $50 \mathrm{gm}$ of dried powdered plant material was mixed with $150 \mathrm{ml}$ of $70 \%$ ethanol and was radiated in microwave oven at 90 second time intervals (30 sec radiation and $1 \mathrm{~min}$ off) to keep temperature not rising above $60^{\circ} \mathrm{C}$. The infusions were allowed to cool down to room temperature, filtered and stored in oven at $40^{\circ} \mathrm{C}$ until dried. 


\section{C- Qualitative Analysis:}

Preliminary qualitative tests (phytochemical screening) were carried out on the extracts to identify the chemical nature and the functional groups of compounds. ${ }^{21}$ The extracts obtained by different methods of extraction where introduced for identification of alkaloids using dragendorff test, ${ }^{22-24}$ flavonoids using alkaline test, ${ }^{25,26}$ antharquinone glycoside using borntrager test, cardioactive glycoside using kellerkilliani test,${ }^{25}$ saponin glycoside using foam test, $^{21}$ tannin using braymers test, ${ }^{1,21,26}$ sterol using libermann-burchard test, terpenoid steroids using salkowkis test, quinone using quinone test, phlobatannin using precipitate test, phenols using ferric chloride test. ${ }^{26}$

\section{Statistical Analysis:}

All the processes of extraction were carried out three times and the mean of the processes was considered as percentage using Microsoft Excel 2007.

\section{Results}

\section{Comparison Of Extraction Methods} Yields:

Comparison was carried out through weighing the yield of each of the extraction methods separately. All the processes of extraction were triplicates expressed in percentage $(w / w)$. The averages of the yields of extraction method are presented in Table 2.

Table 2: Yields of Rosemarinusofficinalis with different methods of extraction.

Method of extraction $\quad$ Yield (\% wiw)

\section{Conventional Extraction Methods}

Maceration (7 days)

Maceration (15 days)

Infusion

Decoction

Ordinary Reflux

Soxhelt

\section{Modern Extraction Methods}

Ultrasound assisted extraction (UAE)

$2.8666 \%$

Microwave assisted extraction (MAE)

\section{$5.3 \%$}

$5 \%$

$4.632 \%$

$3.8 \%$

$5.533 \%$

$6.466 \%$ 
Qualitative Analysis:

The results of preliminary phytochemical screening for extracts of Rosmarinusofficinalis with different methods of extraction are presented in Table 3.

\section{Discussion}

Modern "advanced" extraction methods with beneficial over conventional methods have been developed since medicinal plant extraction methods playing an important roles for providing high quality plant product for the consumer. Extraction process is the most important first step for preparation of the herbal product which affects on the active constituents present in the sample qualitatively and quantitatively. ${ }^{27}$ Average of yields for extraction processes are shown in Table 2 expressed in percentage ( $w / w)$, the soxhelt extraction method with yield $(6.466 \%)$ was the higher yield among the conventional methods with corresponding method in modern method was microwave assisted extraction (MAE) with yield $(7.666 \%)$, which was similar to the finding of Bandar et al. Generally soxhelt extraction method is considered as a well-established method of extraction, moreover in comparison with modern method MAE is consider as an old fashion, time and solvent consuming method. ${ }^{5}$ The advantages of soxhelt extraction method over the other methods belonging to the conventional methods of extraction group, firstly establish an equilibrium of transferring the fresh solvent over the plant material (solid phase), secondly maintenance of elevated temperatures in the container of extraction and finally there was no need for filtration process at the end of the process of extraction. ${ }^{7}$ In comparison of the yields of the two methods of extraction soxhelt and MAE, MAE was considering as a potential alternative methods for the conventional methods. MAE was selected as one of the best methods for extraction of the phytochemicals because lower time consuming, less labor and improving the amount of yield. ${ }^{5,9}$ Other conventional

Table 3: Phytochemical screening of Rosemarinusofficinalis extracts with different methods of extraction.

\begin{tabular}{|c|c|c|c|c|c|c|c|c|}
\hline \multirow{3}{*}{ Phytochemicals } & \multicolumn{8}{|c|}{ Extraction Methods } \\
\hline & \multicolumn{6}{|c|}{ Conventional Extraction Methods } & \multicolumn{2}{|c|}{$\begin{array}{l}\text { Modern Extraction } \\
\text { Methods }\end{array}$} \\
\hline & $\begin{array}{l}\text { Maceration } \\
\text { (7 days) }\end{array}$ & $\begin{array}{l}\text { Maceration } \\
\text { (15 Days) }\end{array}$ & Infusion & Decoction & $\begin{array}{l}\text { Ordinary } \\
\text { Reflux }\end{array}$ & Soxhelt & UAE & MAE \\
\hline Alkaloids & - & - & - & - & - & - & - & - \\
\hline Flavonoids & + & + & + & + & + & + & + & + \\
\hline Anthraquinones & - & - & - & - & - & - & - & - \\
\hline Cardioactive & - & - & - & - & - & - & - & - \\
\hline Saponin & - & - & - & - & - & - & - & - \\
\hline Tannin $(\mathrm{HT})$ & - & - & - & - & - & - & - & - \\
\hline Tannin (CT) & + & + & + & + & + & + & + & + \\
\hline Sterol & - & - & - & - & - & - & - & - \\
\hline Terpenoid & + & + & + & + & + & + & + & + \\
\hline Quinon & + & + & + & + & + & + & + & + \\
\hline Phlobatannin & - & - & - & - & - & - & - & - \\
\hline Phenol & + & + & + & + & + & + & + & + \\
\hline
\end{tabular}

$(+)$ indicates the presence of natural product group, $(-)$ indicates the absence of the natural product. $\mathrm{HT}^{*}$ : refers to the hydrolysable tannins, $\mathrm{CT}^{*}$ : refers to the condensed tannins. 
process of extraction such as maceration was quit time consuming process (3-15 days), decoction high temperatures may affect the active constituents of the plant, infusion was considered a method for extraction of soft parts of plant (restrict usage), ordinary reflux is both time consuming in addition of high temperatures. ${ }^{1,18}$ Modern methods of extraction such ultrasonic assisted extraction process is one of the advanced methods of extraction have many advantages such as easy way of extraction with high efficiency and less destruction of the active constituent since elevated temperatures not used. ${ }^{8}$ In comparison between modern methods of extraction, MAE is preferred over the ultrasound assisted extraction (UAE) because, the MAE increase the mass transfusion through solid matrix of the plant material, faster mixing of the liquid (solvent of extraction) thus maintaining the highest possible driving forces, ensure the highest quantity, quality and purity of the active constituents in the extract, ${ }^{28}$ which support our study. Phytochemical screening of Rosmarinusofficinal is showed the presence of flavonoid, phenols, terpenoid natural product group, and absence of anthraquinone glycoside, cardioactive glycoside, pholobatannin natural products, similar finding were obtained by (Gisleneet $\mathrm{al}^{16}$, Asressu ${ }^{29}$, and Dahiya and Purkayastha ${ }^{30}$. New groups of natural group products were detected in ethanolic extract of Rosmarinusofficinalis which are condensed tannin natural product, tannins were detected in methanolic extract of Rosmarinus officinalis, while the ethanolic extract of Rosmarinusofficinal is shows negative result by Dahiya and Purkayastha 30. Quinone natural product was detected in the ethanolic extract of plant while it was detected in the methanolic extract of plant by Houlihan et $\mathrm{al}^{31}$. About saponin and steroid natural products, there was a controversy our finding similar to the finding of Asressu ${ }^{29}$ regarding the absence of saponin, while they were detected in the ethanolic extract of Rosmarinusofficinalis by Dahiya, Purkayastha ${ }^{30}$. In qualitative analysis among the extracts of Rosmarinusofficinalis found that the phytochemicals (present ones) can be obtained by all the tried methods of extraction using $70 \%$ ethanol (is considered as most effective solvent of extraction $)^{18}$ as solvent of extraction which confirmed by the study done by Milic et al ${ }^{32}$ on Menthe plant using different methods for extraction of menthol. However, the amount of constituents was differing according to the methods of extraction. ${ }^{31}$

\section{Conclusion}

From results we conclude that MAE is the most appropriate method with highest yield mass, less time consuming and little amount of solvent was used for extraction in comparison with other methods of extraction in the two classes of classic and modern. Qualitatively the extracts obtained from all the used methods of extraction contained flavonoids, terpenoid, quinine, phenol and condensed tannin as secondary natural products, but their quantities were not estimated from preliminary phytochemical screening. Further research and studies are recommended about this point. New group of natural product condensed tannin and quinine were detected in the ethanolic extract Rosmarinus officinal is Iraqi Kurdistan species.

\section{Conflicts of interest}

The author reports no conflicts of interest.

\section{References}

1. Handa SS, Khanuja SPS,Longo G, Rakesh DD. Extraction Technologies for Medicinal and Aromatic Plants. International centre for science and high technology Trieste, 2008.

2. Kothari V. Antimicrobial and Antioxidant Properties of Plant Products. Germany: Lambert Academic Publishing (LAP); 2011.

3. Kothari VO, Punjabi AB, Gupta SR. Optimization of microwave assisted extraction of Anonasquamosaseeds. The IcfaiUniv J Life Sci 2009; 3(1): 55-60.

4. Kothari V. Screening of various plant productslextracts for antimicrobial and antioxidant properties and to investigate correlation of 
the latter with phenolic content of sample (Ph.D. Thesis). Nirma University; 2010.

5. Wang L, Weller CL. Recent advances in extraction of nutraceuticals from plants. Trends in Food Science \& Technology 2008;17:300-12.

6. JayanthiP, Lalitha P. Comparison of conventional and sound assisted methods for extraction of Eichhorniacrassipes (MART.) SOLMS. Asian Journal of Pharmaceutical and Clinical Research 2013; 6(1):143-6.

7. Castro LD, Garcia-Ayuso LE. Soxhlet extraction of solid materials: An outdated technique with a promising innovative future. AnalyticaChimicaActa1998; 369:1-10.

8. Vinatoru M. An overview of the ultrasonically assisted extraction of bioactive principles from herbs. UltrasonicsSonochemistry2001; 8:303-13.

9. Kaufmann B, Christen P. Recent extraction techniques for natural products: Microwaveassisted extraction and pressurized solvent extraction. Phytochemical Analysis 2002; 13: 105-13.

10. Chemat F, Tomao V, Virot M. In: Otles, S. (Ed.), Handbook of Food Analysis Instruments -- Ultrasound-Assisted Extraction in Food Analysis 2008, 85-94.

11. Offord EA, Mace K, RuffieuxC, Malnöe A, Pfeiffer AM. Rosemary components inhibit benzopyreneinduced genotoxicity in human bronchial Cells. Carcinogenesis 1995; 16(9):2057-62.

12. Ghahreman A. Chromophites of Iran (Botanical Systematic). University Publication Center, Tehran; 1993.

13. Lo AH, Liang YC, Lin-Shiau SY, Ho CT, Lin JK. Carnosol, an antioxidant in rosemary, suppresses inducible nitric oxide synthase through down-regulating nuclear factor- $\mathrm{KB}$ in mouse macrophages. Carcinogenesis2002; 23:983-91.

14. Ouattara B, Simard RE, Holley RA, Piette GJP, Begin A. Antibacterial activity of selected fatty acids and essential oils against six meat spoilage organisms. International Journal of Food Microbiology1997; 37:155-62.

15. Al-Sereiti MR, Abu-Amer KM, Sen P. Pharmacology of rosemary (Rosmarinusofficinalis L.) and its therapeutic potentials. Ind. J. Exp. Biol1999; 37 (2):124-30.

16. Gislene NGF, Juliana L, Freitas PC, Giuliana LS. Antibacterial Activity of Plant Extracts and Phytochemicals on Antibiotic Resistant Bacteria. Braz J Microbiol2000; 31:247-56.

17. Frankel EN. Antioxidant activity of a rosemary extract and its constituents, carnosic acid, carnosol, and rosmarinic acid, in bulk oil and oil-in -water emulsion. Journal of Agricultural and Food Chemistry 1996; 44(1):131-35.

18. Bandar $H$, Hijazi $A$, Rammal $H$, Hachem $A$, Saad Z, Badran B.Techniques for the Extraction of Bioactive Compounds from Lebanese Urticadioica. American Journal of Phytomedicine and Clinical Therapeutics2013;1(6):507-13.
19. Alupuli A, Calinescu I, Lavric V. Ultrasonic vs. microwave extraction intensification of active principles from medicinal plants. AIDIC Conference Series2009; 09, 1-8.

20. Quan PT, Hang TV. Microwave assisted extraction of polyphenols from fresh teashoot. TAP CHI TRIEM KH \& CN 2006; 9(8):69-75.

21. Banso A. Phytochemical and antibacterial investigation of bark extracts of Acacia nilotica. J. Med. Plants Res.2009; 3:82-5.

22. Evans WC. Trease and Evans pharmacognosy. UK, Elseveir; 2000.

23. Harborn JB. In: Phytochemistery methods. New York,Wiely; 1984.

24. Seema E. Isolation and identification of cyaniding pigment from Allium cepa $\mathrm{L}$. and its application as antioxidant. M.Sc. Thesis. University of Basra; 2008.

25. AshutushKar. Pharmacognosy and pharmacobiotechnology. New age international, K.K.Gutpa, New Delhi; 2008.

26. Ugochukwu SC, Arukwe UI, Ifeanyi O. Preliminary phytochemical screening of different solvent extracts of stem bark and roots of Dennetiatripetala G. Baker. Asian Journal of Plant Science and Research 2013; 3(3):10-3.

27. Carmen WH. A review of modern samplepreparation techniques for the extraction and analysis of medicinal plants. Anal Bioanal. Chem2002; 373:23-30.

28. Alupului A, Calinescu I, Lavric V. Ultrasonic vs. Microwave Extraction Intensification of Active Principles from Medicinal Plants. AIDIC conference, 2009; volume 9.

29. Asressu $\mathrm{KH}$. Antimicrobial activity and phytochemical screening of crude Extracts of medicinal plants grown in eastern Ethiopia.Int. J Pharm Bio Sci 2013; 4(4):326-33.

30. Dahiya P,Purkayastha S. Phytochemical screening and antimicrobial activity of some medicinal plants against muti- drug resistant bacteria from clinical isolates. Indian J.PharmSci 2012; 74 (5):443-50.

31. Houlihan CM, HoCT, Chang SS. The structure of rosmariquinone: a new isolated from Rosmarinusofficinalis L. J. Am Oil ChemSoc 1985; 62:96-8.

32. Milic S, Lepojevic Z, Adamovic D, Mujic I,Zekovic $Z$. Comparison of menthe extracts obtained by different extraction methods. APTEFF2006; $37: 145-54$ 